Produto \& Produção, vol. 11, n. 1, p. 89 - 98, fev. 2010

Edição Metrologia

\title{
Implementação da NBR 17025:2005 no Laboratório de Metalurgia Física (LAMEF) Visando à Confiabilidade na Realização de Ensaios em Implantes
}

\author{
Etiene Benini Mendes, Eng ${ }^{a}$ \\ Laboratório de Metalurgia Física, Programa de Pós-Graduação em Engenharia de Minas, \\ Metalúrgica e de Materiais, UFRGS \\ etiene@demet.ufrgs.br \\ Afonso Reguly, Prof Dr \\ reguly@demet.ufrgs.br \\ Telmo Roberto Strohaecker, Prof Dr \\ telmo@demet.ufrgs.br
}

\section{RESUMO}

Este trabalho tem por objetivo apresentar as principais etapas da implementação da NBR 17025:2005 no Laboratório de Metalurgia Física (LAMEF) da UFRGS com foco na realização de ensaios em implantes e as mudanças decorrentes deste processo.

Palavras-chave: NBR 17025; implementação; laboratório, implantes.

\section{INTRODUÇÃO}

A implantação de materiais metálicos no corpo humano é considerada como uma alternativa para restaurar partes danificadas, melhorando assim a qualidade de vida do paciente após traumas ou ainda no caso de doenças degenerativas [1]. Esses materiais são chamados de biomateriais e devem ter sua escolha baseada em critérios como propriedades mecânicas adequadas para o uso, não interferência no sistema de defesa do organismo, resistência à corrosão, entre outros. Os implantes metálicos podem ser produzidos em ligas de Titânio, Cromo-Cobalto e de Aço Inoxidável AISI 316L, sendo que este último é um dos mais utilizados tendo em vista o seu baixo custo quando comparado com as outras duas ligas.

Um implante de qualidade é feito para durar, em média, entre 12 e 20 anos, dependendo do material empregado na sua fabricação. As conseqüências mais comuns da utilização de implantes inadequados são basicamente três: o desgaste precoce, a quebra do material e a metalose. Essa última é provavelmente a pior delas. Com o passar dos anos e em contato com fluídos do corpo humano, a peça feita de material de baixa qualidade pode provocar reações no organismo e este começar a liberar uma substância de coloração negra e pastosa (se assemelha à graxa automotiva), que pode chegar à circulação sanguínea e causar sérias 
infecções. Em casos mais graves, pode, ainda, levar a amputação do membro afetado e até a morte do paciente.

Nos casos em que o implante falha prematuramente, cirurgias de revisão ou reparo são necessárias para que a troca do implante seja realizada. Essa segunda cirurgia sempre causa um trauma no paciente e representa um custo extra para o Sistema Único de Saúde (SUS).

Para evitar que esse tipo de situação continue a se repetir, já existe uma mobilização governamental. A tradução e elaboração de normas importantes para a garantia da qualidade dos implantes, como especificações de ligas e propriedades mecânicas, é uma realidade bastante recente. A utilização dessas normas já é, em muitos casos, exigida para o registro do implante junto à ANVISA (Agência Nacional de Vigilância Sanitária). Em paralelo se observa uma preocupação do governo em qualificar instituições científicas para a realização dos ensaios que garantam a qualidade do implante. Um exemplo que pode ser citado foi o investimento dos Ministérios da Saúde e Ciências e Tecnologia na capacitação e melhoria da infraestrutura de instituições científicas através de chamada pública em 2005. As instituições que tiveram seus projetos aprovados, hoje formam a Rede Multicêntrica de Avaliação de Implantes Ortopédicos (REMATO) que tem como objetivo o desenvolvimento de metodologias, procedimentos e dispositivos de ensaios de avaliação para implantes ortopédicos.

O LAMEF, como membro da REMATO, tem buscado melhorar a sua capacitação para a realização de ensaios em implantes. A principal medida adotada pelo laboratório para atingir este objetivo foi a implementação da NBR ISO/IEC 17025:2005, visando a acreditação futura junto ao INMETRO.

A NBR ISO/IEC 17025 foi publicada no ano de 2001 em substituição ao ISO/IEC Guia 25 de 1993 e revisada em 2005. Ela descreve os mecanismos para evidenciar a competência técnica dos laboratórios na realização de calibrações e/ou ensaios. A norma é estruturada em duas partes: os requisitos da direção e os requisitos técnicos e deve ser utilizada por laboratórios no desenvolvimento dos seus sistemas de qualidade, administração e técnicas que regem suas operações. Com o auxilio da NBR 17025, clientes, autoridades regulamentadoras e organismos de acreditação podem realizar auditorias e verificar a competência do laboratório para a realização do serviço[2].

\section{MÉTODOS}

\subsection{Instituição}

O Laboratório de Metalurgia Física (LAMEF) é um laboratório universitário ligado ao Departamento de Metalurgia da Escola de Engenharia da UFRGS.

Sob a Coordenação do Prof. Dr. Telmo Strohaecker, o laboratório conta hoje com mais dois Professores, quatro engenheiros e um técnico do quadro de funcionários da UFRGS, que em conjunto com alunos de graduação e pósgraduação formam a equipe do laboratório.

A equipe está dividida em quatro sedes sendo elas, a Escola de Engenharia Nova e o prédio Histórico do Chatêau localizados no Campus Central, o prédio 74 do Setor IV e a Casa de Desenvolvimento Tecnológico (CADETEC) localizados no 
Campus do Vale onde são desenvolvidos os trabalhos de pesquisa e um laboratório de ensino no Setor IV do Campus do Vale.

As áreas de pesquisa são divididas por Grupos, que podem trabalhar independentemente, em conjunto com outros grupos ou em parceria com empresas, através da forma de convênios.

Para o sistema de gestão da qualidade do Laboratório, os Grupos de Pesquisa são: Grupo de Análise de Falhas (GAF), Grupo de Projeto em Engenharia (ProEng), Grupo de Ensaios Não-Destrutivos (GEND), Grupo de Ensaio em Corrosão à Fadiga (GECOR), Grupo de Ensaios Mecânicos (GEM) e Grupo de Robótica, Controle e Automação (RCA).

\subsection{Definição da estratégia}

Para dar início ao trabalho de implementação da NBR ISO/IEC 17025, foi definido em conjunto com a Alta Direção do LAMEF o primeiro Grupo a ter o Projeto implementado.

O Grupo de Análise de Falhas (GAF) foi o escolhido em função de anteriormente já ter iniciado um trabalho de implementação de Sistema de Qualidade e porque naquele momento era o grupo que mais realizava ensaios em implantes.

Como o próprio nome já diz, o grupo realiza análise de falhas em componentes mecânicos e biomédicos. Os principais ensaios realizados são: análise metalográfica, ensaios de dureza e microdureza, análise química via espectrometria de emissão óptica, análise microscópica via microscópio eletrônico de varredura (MEV) e análise química via EDS. A realização destes ensaios permite, por exemplo, determinar a causa de falhas em componentes e verificar se o componente atende especificações normativas.

Durante a implementação da norma, que iniciou em 2006, observou-se uma demanda crescente na solicitação de ensaios mecânicos para avaliação de implantes. Dessa forma, o sistema de gestão começou a ser estendido também para o GEM, Grupo de Ensaios Mecânicos.

\section{RESULTADOS E DISCUSSÕES}

\subsection{Implementação dos requisitos técnicos}

O trabalho de implementação da norma começou primeiramente com a introdução dos requisitos técnicos, ou seja, o requisito 5 da NBR 17025.

\subsubsection{Acomodações e condições ambientais}

De acordo com a norma, é necessário que exista a separação efetiva entre áreas vizinhas nas quais existam atividades incompatíveis. O controle de acesso à 
área de ensaio também deve ser controlado. Por isso, o lay out interno do laboratório foi alterado. Os equipamentos de ensaio, que antes ficavam em diversas salas do laboratório, foram realocados para um único ambiente, com controle de temperatura e umidade. A área do café, que estava próxima da realização dos ensaios foi deslocada para um ambiente em separado. O controle de acesso às áreas de ensaios é feito com uso de senha.

\subsubsection{Métodos de ensaio}

Ao mesmo tempo em que começaram as alterações de lay out, os procedimentos operacionais e de ensaios passaram a ser elaborados. Para elaboração dos procedimentos operacionais (como operar o equipamento), foram utilizados como base os manuais dos equipamentos fornecidos pelos fabricantes. Para elaboração dos procedimentos de ensaios (como fazer o ensaio), foram utilizadas como base normas ABNT e ASTM. Mas em ambos os casos, a rotina já estabelecida pelo pessoal que opera os equipamentos e realiza os ensaios foi considerada e ajustada com os manuais e normas.

\subsubsection{Pessoal}

A partir da elaboração destes procedimentos, o pessoal passou a receber treinamentos para uso correto dos equipamentos e realização dos ensaios. Membros de outros grupos do laboratório que queiram utilizar a estrutura do GAF e do GEM, devem antes realizar treinamentos para que tenham o uso dos equipamentos liberados.

Os treinamentos são dados utilizando-se como base os procedimentos já elaboradores. É também durante esses treinamentos que os procedimentos são revisados e quando necessários são melhorados com sugestões do pessoal que está sendo treinado. Esta é maneira de fazer com que as pessoas se sintam realmente fazendo parte do sistema de gestão do laboratório. Após o treinamento, são realizadas avaliações para que a eficácia do treinamento seja comprovada.

Além dos procedimentos de ensaios e operacionais estarem disponíveis ao lado dos equipamentos e nos locais de ensaio, os membros do grupo contam com dois livros que contém todos os procedimentos (um com os operacionais e outro com os de ensaio). Esses livros tem como finalidade aproximar ainda mais o pessoal das técnicas corretas. Neste material é permitido que o pessoal faça anotações e sugira melhorias nos procedimentos. Além disso, mensalmente são realizadas 'auditorias de padrão'. Um auditor interno do laboratório, mas que não faça parte do grupo auditado, escolhe aleatoriamente membros do grupo e procedimentos para serem auditados. Nesta auditoria, além de verificar se a pessoa está seguindo o procedimento corretamente, são avaliadas questões como:

- a atenção e o foco durante a realização da atividade;

- se conhece, domina e exerce de forma adequada e segura as tarefas a serem executadas, bem como os resultados que devem ser obtidos;

- possui entendimento do processo e não somente da tarefa. Conhece os processos da área e cumpre os padrões específicos da sua atividade. 
Após as auditorias, os relatórios são analisados e são elaborados planos de ações, que podem incluir ações para eliminação de uma nãoconformidade detectada ou por em prática alguma oportunidade de melhoria.

\subsubsection{Equipamentos}

Com a aquisição de um novo equipamento de análise química via emissão óptica passou a ser possível a análise de implantes de ligas de Titânio e de CromoCobalto. Para a análise de implantes de aço inoxidável, o laboratório já possuía um equipamento.

Para a realização dos ensaios mecânicos foi adquirida mais uma máquina de ensaios sevo-hidráulica, totalizando assim três equipamentos e permitindo assim o aumento do escopo de ensaios mecânicos.

Além disso, cada equipamento passou a ter uma ficha de registro, onde constam suas informações técnicas e manutenções. Junto com essa ficha, também ficam, em uma pasta, o manual do equipamento, certificado de calibração (quando o equipamento necessitar) e outros documentos relacionados ao equipamento. Essa nova organização dos documentos relacionados aos equipamentos tem permitido maior agilidade quando se necessita de alguma informação referente aos mesmos.

Programas de Manutenção Autônoma foram criados para diminuir o tempo de máquina parada e aumentar a produtividade dos ensaios. O registro das manutenções já realizadas com suas devidas anotações facilita quando surge um problema semelhante ao já ocorrido anteriormente.

\subsubsection{Apresentação de resultados}

O relatório de ensaio emitido pelo laboratório foi reformulado para atender aos requisitos da norma. Informações como metodologia utilizada e norma na qual foram baseados os ensaios apresentados foram incluídas. Essas alterações foram introduzidas sem que se perdesse a maior característica dos relatórios do LAMEF, que é tentar passar o maior número de informações possíveis para o cliente e não somente um resultado de ensaio sem nenhuma explicação. Isso acontece principalmente nos relatórios de análise de falha, onde o cliente enxerga não somente os resultados quantitativos das análises, mas uma provável causa da falha do implante.

\subsection{Implementação dos requisitos da direção}

Os requisitos de direção começaram a ser implementados com a definição da política de qualidade, missão, visão e objetivos estratégicos do laboratório. Em cima dessas definições, o sistema de gestão começou a ser montado. 


\subsubsection{Sistema de Gestão e Controle de Documentos}

Para elaboração da documentação do laboratório, foram definidos os seguintes níveis:

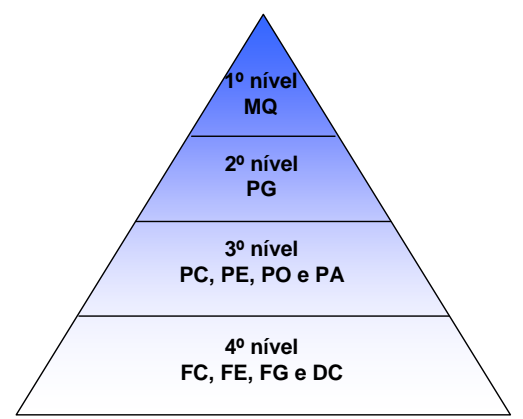

Figura 1: Estrutura da documentação do laboratório.

Onde, MQ é o Manual da Qualidade, PG são Procedimentos Gerencias, sendo estes 2 níveis comuns a todos os grupos, PC são Procedimento de Calibração, PE são Procedimentos de Ensaios, PO são Procedimentos Operacionais e PA são Procedimentos Auxiliares. FC são os Formulários de Calibração, FE são Formulários de Ensaios, FG são Formulários Gerais e DC são Documentos Complementares. Os níveis 3 e 4 da documentação são específicos de cada grupo e possuem em sua nomenclatura, antes do tipo de procedimento, o nome do grupo. Como por exemplo, GAF - PE 001.

Apesar de o trabalho de implementação da NBR 17025 ter começado pelo GAF, a estrutura da documentação foi montada de maneira que quando se percebesse a necessidade da extensão da mesma para os demais grupos, isso se tornaria possível sem grandes alterações no Sistema.

Sendo assim, quando as solicitações de ensaios mecânicos para avaliação de implantes começaram a aumentar, o sistema de gestão implementado no GAF foi entendido também ao GEM.

Além disso, foi elaborado um documento, que serve de orientação para a introdução dos projetos de pesquisa dentro do Sistema de Gestão, sem que o Sistema fique inchado e desatualizado ao longo dos anos.

Ainda dentro do Sistema de Gestão do laboratório, foram definidos os indicadores, tendo como base os objetivos estratégicos do LAMEF (sempre sem perder o foco de que o laboratório é universitário e atende aos setores de pesquisa, extensão e formação de recursos humanos).

\subsubsection{Análise Crítica de Pedidos, Propostas e Contratos e Controle de Registros}

Para a análise crítica de pedidos, propostas e contratos foi elaborado um questionário que incluísse todas as solicitações da norma. Para evitar que o colaborador esqueça de preencher este documento, o questionário foi introduzido no software de solicitação de serviços. Atualmente, só é possível abrir uma solicitação 
se todas as etapas forem seguidas. Primeiro é necessário preencher a análise crítica da solicitação. Sendo possível a realização do serviço, o software abrirá a tela para elaboração do orçamento. Finalizado o orçamento, o mesmo será enviado via e-mail para o cliente através do próprio sistema. Somente com o aceite do cliente é que o link para abertura da solicitação de serviço estará liberado.

Enquanto o item de ensaio estiver sendo manuseado dentro do laboratório, todos os registros pertinentes ao trabalho são arquivados em uma pasta eletrônica dentro de um servidor. Entre esses registros, encontram-se inclusive os e-mails trocados com o cliente e que possam de alguma forma contribuir com o trabalho. Após o encerramento do trabalho essa pasta eletrônica (contento inclusive o relatório final do ensaio) é carregada no mesmo software de solicitação de serviço.

Esse tipo de ação permite que se tenha um total controle da realização do ensaio, desde a solicitação inicial do cliente, até o relatório final. Se por ventura, em algum momento futuro o trabalho for questionado ou alguma não-conformidade for verificada, é possível rastrear tudo o que diz respeito a determinado trabalho.

\subsection{Análise de Dados}

Analisando-se os dados de 2006 até o presente momento, percebe-se um aumento do número de relatórios de ensaios em implantes realizados pelo LAMEF em relação ao número total de relatórios emitidos, conforme observa-se na tabela 1.

Tabela 1 - Relatórios de ensaios de implantes emitidos em relação ao número total de relatórios de ensaios emitidos. (* até 31/07/2009)

\begin{tabular}{|c|c|}
\hline Ano & Ensaios em Implantes \\
\hline 2006 & $18 \%$ \\
\hline 2007 & $32 \%$ \\
\hline 2008 & $38 \%$ \\
\hline $200{ }^{*}$ & $26 \%$ \\
\hline
\end{tabular}

Também é possível notar as alterações na demanda de ensaios, que durante os anos de 2006 e 2007 tinham sua concentração na área de análise de falhas e desde o ano passado concentram-se na realização de ensaios mecânicos, como mostra a tabela 2. Em 2006, por exemplo, 67\% dos relatórios de ensaio em implantes emitidos pelo LAMEF foram para determinar a causa de falha de um componente, enquanto somente $33 \%$ foram para a realização de algum tipo de ensaio mecânico em implante. É importante ressaltar que esses números não representam a quantidade de amostras/componentes ensaiadas e sim o número de relatórios emitidos.

Tabela 2 - Relatórios de análise de falha em implantes e relatórios de ensaios mecânicos. (* até 31/07/2009)

\begin{tabular}{|c|c|c|}
\hline Ano & Análise de Falhas & Ensaios Mecânicos \\
\hline 2006 & $67 \%$ & $33 \%$ \\
\hline 2007 & $57 \%$ & $43 \%$ \\
\hline 2008 & $11 \%$ & $89 \%$ \\
\hline $2009^{\star}$ & $14 \%$ & $86 \%$ \\
\hline
\end{tabular}


Essa alteração pode ser explicada pelo aumento do escopo de ensaios mecânicos que foi possível com a aquisição de novos equipamentos, como a máquina de ensaios servo-hidráulica e a máquina para análise dimensional e de rugosidade.

Analisando-se os percentuais por tipos de implantes, as análises de falha encontram-se na tabela 3 e os ensaios mecânicos na tabela 4.

Tabela 3 - Análises de falhas por tipo de implantes. ( ${ }^{\star}$ até 31/07/2009).

\begin{tabular}{|c|c|c|c|}
\hline Ano & Ensaio & Implante & Percentual \\
\hline \multirow{6}{*}{2006} & \multirow{6}{*}{ Análise de Falha } & Placas & $6 \%$ \\
\hline & & Parafuso & $23 \%$ \\
\hline & & Joelho & $18 \%$ \\
\hline & & Coluna & $35 \%$ \\
\hline & & Quadril & $14 \%$ \\
\hline & & Hastes Intr & $4 \%$ \\
\hline \multirow{6}{*}{2007} & \multirow{6}{*}{ Análise de Falha } & Placas & $7 \%$ \\
\hline & & Parafuso & $9 \%$ \\
\hline & & Joelho & $10 \%$ \\
\hline & & Coluna & $5 \%$ \\
\hline & & Quadril & $48 \%$ \\
\hline & & Hastes Intr & $21 \%$ \\
\hline \multirow{6}{*}{2008} & \multirow{6}{*}{ Análise de Falha } & Placas & $64 \%$ \\
\hline & & Parafuso & $9 \%$ \\
\hline & & Joelho & $0 \%$ \\
\hline & & Coluna & $9 \%$ \\
\hline & & Quadril & $9 \%$ \\
\hline & & Hastes Intr & $9 \%$ \\
\hline \multirow{6}{*}{$2009^{*}$} & \multirow{6}{*}{ Análise de Falha } & Placas & $40 \%$ \\
\hline & & Parafuso & $0 \%$ \\
\hline & & Joelho & $0 \%$ \\
\hline & & Coluna & $0 \%$ \\
\hline & & Quadril & $20 \%$ \\
\hline & & Hastes Intr & $40 \%$ \\
\hline
\end{tabular}

Tabela 4 - Ensaios mecânicos por tipo de implantes. (* até 31/07/2009). 


\begin{tabular}{|c|c|c|c|}
\hline Ano & Ensaio & Implante & Percentual \\
\hline \multirow{6}{*}{2006} & \multirow{6}{*}{ Ensaio Mecânico } & Placas & $0 \%$ \\
\hline & & Parafuso & $20 \%$ \\
\hline & & Joelho & $16 \%$ \\
\hline & & Coluna & $12 \%$ \\
\hline & & Quadril & $4 \%$ \\
\hline & & Hastes Intr & $48 \%$ \\
\hline \multirow{7}{*}{2007} & \multirow{7}{*}{ Ensaio Mecânico } & Placas & $36 \%$ \\
\hline & & Parafuso & $14 \%$ \\
\hline & & Joelho & $5 \%$ \\
\hline & & Coluna & $5 \%$ \\
\hline & & Quadril & $2 \%$ \\
\hline & & Hastes Intr & $9 \%$ \\
\hline & & Outros & $29 \%$ \\
\hline \multirow{7}{*}{2008} & \multirow{7}{*}{ Ensaio Mecânico } & Placas & $2 \%$ \\
\hline & & Parafuso & $38 \%$ \\
\hline & & Joelho & $0 \%$ \\
\hline & & Coluna & $5 \%$ \\
\hline & & Quadril & $0 \%$ \\
\hline & & Hastes Intr & $48 \%$ \\
\hline & & Outros & $7 \%$ \\
\hline \multirow{7}{*}{$2009 *$} & \multirow{7}{*}{ Ensaio Mecânico } & Placas & $10 \%$ \\
\hline & & Parafuso & $6 \%$ \\
\hline & & Joelho & $0 \%$ \\
\hline & & Coluna & $3 \%$ \\
\hline & & Quadril & $0 \%$ \\
\hline & & Hastes Intr & $58 \%$ \\
\hline & & Outros & $23 \%$ \\
\hline
\end{tabular}

\section{CONCLUSÃO}

As mudanças ocorridas no LAMEF desde o início da implementação da norma são visíveis, tanto em termos de infraestrutura quanto em termos culturais. $O$ lay out do laboratório foi adequado para atender aos requisitos de ensaios e novos equipamentos foram adquiridos.

A estratégia adotada para a implementação da NBR 17025 no laboratório tem se mostrado bastante adequada, uma vez que tem permitido ao laboratório aumentar o seu escopo de ensaios mantendo a qualidade na prestação do serviço.

Atualmente o sistema de gestão encontra-se plenamente implementado em três grupos de ensaio (GAF, GEM e PROENG) e as equipes envolvidas neste projeto estão finalizando a solicitação de acreditação junto ao INMETRO.

\section{ABSTRACT}

This paper aims to present the main steps of the implementation of NBR 17025:2005 by the Laboratory of Physical Metallurgy (LAMEF) UFRGS focused on testing of implants and the changes of this process.

Keywords: implementation; laboratory implants. 


\section{REFERÊNCIAS}

[1] FONSECA, K.B.; PEREIRA, H.H.; SILVA, S.N., Avaliação de Falhas em Implantes Metálicos Coxo-Femoral e Joelho Retirados de Pacientes. Revista Matéria, v. 10, n. 3, pp. 472 - 480, 2005.

[2] MAGALHÃES, J.G.; NORONHA, J.N.; Sistema de gestão da qualidade para laboratório de metrologia de acordo com a NBR ISO/IEC 17025:2005. XXVI ENEGEP, outubro/2006, Fortaleza/CE.

[3] ABNT - Associação Brasileira de Normas Técnicas; NBR ISO/IEC 17025 Requisitos gerais para competência de laboratórios de ensaio e calibração, 2005.

[4] JORNADA D.H, PIZZOLATO M., RAYA-RODRIGUEZ M.T. e RODRIGUES M.S.; Adequação de Laboratórios aos requisitos da norma NBR ISO/IEC 17025:2001 - Um estudo de caso em laboratórios de análises ambientais. Metrosul IV, Rede Paranaense de Metrologia e Ensaios, nov/2004, Foz do Iguaçu/PR. Em CD-ROM

[5] JÚNIOR L.S., ROCHA A.S. E LIMA C.R.G; Acreditação do Laboratório de Pressão da Universidade Federal do Ceará. Metrosul IV, Rede Paranaense de Metrologia e Ensaios, nov/2004, Foz do Iguaçu/PR..Em CD-ROM

[6] CASTRO A.F., SILVA G.M.P. e SANTOS S.F.; O controle de documentos mantidos em meio eletrônico e os requisitos da NBR ISO/IEC 17025. Metrosul IV, Rede Paranaense de Metrologia, nov/2004, Foz do Iguaçu/PR. Em CD-ROM.

[7] MARTORELLI L.C. e MARTINI C.A; Implementacion de metrologia óptica através de la norma ISO/IEC 17025 em microscopia. Metrologia 2000, Sociedade Brasileira de Metrologia, dez/2000, São Paulo/SP. Em CD-ROM. 